\title{
Progressive Disease
}

National Cancer Institute

\section{Source}

National Cancer Institute. Progressive Disease. NCI Thesaurus. Code C35571.

A disease process that is increasing in scope or severity. 